\title{
DESIGN FOR DUCHENNE. Guidelines for dwellings' construction or renovation for Muscular Dystrophy-Affected Families
}

\section{Michele Marchi \& Giuseppe Mincolelli}

To cite this article: Michele Marchi \& Giuseppe Mincolelli (2017) DESIGN FOR DUCHENNE. Guidelines for dwellings' construction or renovation for Muscular Dystrophy-Affected Families, The Design Journal, 20:sup1, S2068-S2077, DOI: 10.1080/14606925.2017.1352725

To link to this article: https://doi.org/10.1080/14606925.2017.1352725

(c) 2017 The Author(s). Published by Informa UK Limited, trading as Taylor \& Francis Group

\section{曲 Published online: 06 Sep 2017.}

Submit your article to this journal $₫$

Џ Article views: 418

Q View related articles $₫$

View Crossmark data $\circlearrowright$ 


\title{
DESIGN FOR DUCHENNE. Guidelines for dwellings' construction or renovation for Muscular Dystrophy-Affected Families
}

\author{
Michele Marchi ${ }^{{ }^{*}}$, Giuseppe Mincolelli ${ }^{{ }^{* *}}$ \\ a University of Ferrara, Department of Architecture of Ferrara, via della Ghiara 36, 44121 Ferrara, Italy \\ *Corresponding author e-mail: michele.marchi@unife.it \\ **Corresponding author e-mail: giuseppe.mincolelli@unife.it
}

\begin{abstract}
The Duchenne muscular dystrophy (DMD) is a rare disease that affects 1one Boy of about 3500. The first symptoms appear in about 2-5 years and lead to a total paralysis. The current average life expectancy is $25-30$ years.

The Italian legislation on the accessibility of the spaces is outdated and not relevant to a consumer complex as that dystrophic.

The research aims to produce an information and knowledge tool useful both for families and for professionals to inform them on the technological opportunities in the market and tries to suggest the types more accessible based on the current and future needs of boys with DMD.

The entire project, which follows the multidisciplinary approach of Design for All, was developed following the methodology of the Quality Function Deployment (QFD), a technique that puts users at the center of the creative project and ideational.

The research has also led to a monographic publication published by Franco Angeli Editore.
\end{abstract}

Keywords: disability, accessibility, Design for All, architectural barriers, User Centered Design, QFD.

\section{Introduction}

This research project was developed in virtue of the collaboration between the Architecture Department of The University of Ferrara and Parent Project Onlus. This organization began its work in 1996 thanks to a group of parents whose children were affected by dystrophic syndrome. Their goal was to generate and subsidize medical trials, aiming at uncovering the final cure allowing Duchenne people to relieve from the disease; unfortunately, after about 10 years no crucial cure has been discovered yet, but many different rehabilitation processes allowing Duchenne children to double their life span have been devised. 
Thanks to such processes, life quality acquires different features compared to previous situations, and therefore many families have felt the need to equip their dwellings according to their children's new abilities/disabilities.

Thus far, there are no appropriate instruments for informing families on such specific topic and issues.

By virtue of an agreement between Parent Project Onlus and the University of Ferrara, a PhD research scholarship was activated specifically for filling this gap.

The objective of the research was to provide both families and specialists with an adequate tool for receiving information on domestic accessibility addressing a complex set of users as the dystrophic ones.

Research also aimed at analyzing the relationships between the individual and the environment, grounding on the progression of the disease. Through the 'User Centered Design App' a list of needs coming from the involved people has been reported, then selecting all the positive and negative effects of the best solutions available on the market today, in order to finally develop recommendations focused on the spatial, functional, and morphological fulfillment of the domestic environments and their furnishings.

\section{The Duchenne Muscular Dystrophy}

Duchenne muscular dystrophy (DMD) is one of the many existing dystrophies, all of which having in common the lack and/or deficiency of dystrophin: a protein contained within the membrane of the muscular fiber. DMD and Becker muscular dystrophy (BMD) are two of the prevalent and most known dystrophin diseases, yet presenting different characteristics. In DMD dystrophin is lowered or altered, and therefore it will bring to the complete paralysis of all body muscles; first symptoms appear between two and four years of age. Instead, in BMD symptoms can display also in later life, and with complexities and muscular paralysis of minor disabling impact.

DMD is an infrequent disease ${ }^{1}$, striking 1 male child in 3.500 live births. It is estimated that in Italy there are about 5.000 people affected by this illness, but there are no official data coming from protocols; furthermore, reference centers, diagnosis, cure management and a specific database are still lacking.

DMD is the most known among all muscular dystrophies and it strikes almost exclusively male children, as the syndrome presents a gene alteration on the $\mathrm{X}$ chromosome.

Due to a dearth of dystrophin, the cells on the muscular tissue are more sensitive and less protected from external agents, causing their explosion and consequent death.

As a result, the dead cell's content poured out outward gets cleaned by our immune system; however, this wipes out a bigger part of what would be necessary, therefore including fragments of the healthy muscular system. Such process causes a greater harm than the initial one, and the "vacuum" it creates is replaced by connective tissue. Through the phenomenon reiteration, the muscle becomes more and more damaged, and the healthy cells end up "suffocated". Constant repetition of this model eventually brings to the complete death of all muscular cells.

1 - A disease is considered "rare" when it affects no more than 5 in 10,000 people. 
First symptoms of this disease appear around two to four years of age, and display through a difficulty to stand up from the ground, climb the stairs, freely run around. What needs to be clarified is that there are no standards referring to symptoms and their appearance; studies on DMD are relatively recent, and thus also the analysis and investigation systems are constantly changing and evolving.

What does exist is a classification of disability referring to the lower limbs ${ }^{2}$ :

- ambulant patient: first evolutionary step of the Duchenne syndrome coincide with the infant's first years of age. First disease symptoms, as already stated, display around 24 years, even though it is still quite premature to clearly notice the first manifestations of disability, if not to an expert and good eye.

- Partially ambulant with assistance needs: second phase of the disease is characterized by the first signs of reduced mobility (around 5-10 years). The child is capable of walking, but the first mobility issues appear; the disease progression then affects the vertebral column stressing lordosis -physiologically present in children- due to the weakening of the pelvic muscle group. Children enter adolescence and begin to understand their abilities/disabilities, hence all the psychological implications of this phase are extremely significant.

- Non-ambulant patient, stage 1: during this phase, which corresponds to the apical years of adolescence (11-18 years), a drastic change in a Duchenne individual occurs. Principal aspects of this stage are the introduction of the electric wheelchair, individual growth with the integration in Middle School, the beginning of the teenage period, new interests and the management of the networks of friends.

- Non-ambulant patient, stage 2: since 18 years of age the disabled person steps into the adulthood handicap services, and this marks the division between the activities followed by the pediatrician and those followed by the general practitioner. This clear separation from a bureaucratic/regulatory point of view is not associated to a distinction in the child's needs, if not to a regular progression of the disease. At this point, the patient has lost control over the lower limbs, and begins to manifest an important disability also in the upper limbs; therefore, many of the daily activities become unfeasible or very restricted.

This phase will eventually lead to the patient's death, most of the times due to cardiac or respiratory problems.

Up to today, there are no classifications of the upper limbs, thence all performances needs to be analyzed case by case.

Duchenne muscular dystrophy is a degenerative disease, quite complicated because of its constant evolution; as a consequence of such transformation, also the household dynamics, the use of domestic spaces, and the relations that users have with the supports need to change and evolve.

2 - The classification of the lower limbs is quite unanimous and full blown. Moreover, such codification can concern all forms of muscular dystrophy or neuromuscular diseases. University of Ferrara, Department of Medical-Surgical Sciences of Communication and Behavior. Section of Clinical Neurology. Director: Prof. Enrico Granieri. A classification of the upper limbs has not been developed yet, as the variables are multiple and they can vary from patient to patient. However, recent studies in this field are investigating and trying to find solid modalities for identifying the symptoms (see: Mayhew, A., Mazzone, E. S., Eagle, M., Duong, T., Ash, M., Decostre, V., ... \& Bianco, F. (2013). Development of the Performance of the Upper Limb module for Duchenne muscular dystrophy. Developmental Medicine \& Child Neurology, 55(11), 1038-1045. Available at:

http://onlinelibrary.wiley.com/doi/10.1111/dmcn.12213/full [accessed 3/11/2016]). 
There is still no complete cognizance of the disease, but thanks to an accurate study it has been possible to trace some behavioral standards; referring to those, a family will have the chance to plan its life and try to be ready for the appearance of future disabilities.

In fact, it would be best not to be taken by surprise because possible dwelling or behavioral modifications -if not tackled and adapted in time- could reveal themselves detrimental for both the objectives and the psychological and emotional implications of a DMD child.

\section{Accessibility Issues for DMD Person}

It is within the above-stated context that the Parent Project Onlus asked for help and support to the Architecture Department of Ferrara, trying to find new design solutions for improving DMD affected people's everyday life.

The main goal of the research proposed by Parent Project is quite complex: on one hand because of the involved users, for DMD represents one of the most problematic pathologies ever studied; on the other hand, because the regulatory framework of reference is not always proper and exhaustive for such a complex and degenerative disease as dystrophy is.

The Italian legislation for the elimination of architectural barriers and for adaptability, visibility, and accessibility in private residential environments is represented by the law 13/1989 and by the Ministerial Decree 236/1989. However, such norms -quite innovative and inclusive for the time they were conceived- have been built especially around the needs and conditions of tetra-paraplegic and partially sighted people; consequently, all those individuals with a disability of other form or nature are excluded from those prescriptions.

A designer facing the needs of a disabled client tries to comply the prescriptions coming from the law, considering them quite sufficient for providing accessible environments. Unfortunately, today we have learnt that following such process is not appropriate; every disabled person has its own abilities and disabilities, and slavishly follow the law does not represent a virtuous and worthy attitude, for there are obsolete and not updated recommendations if referring to muscular degenerative dystrophy.

The occasion in which a family learns from the doctors their son is affected by DMD represents a critical moment for everybody's lives; a condition of total dismay, as nobody knows exactly what is best for containing as much as possible the child's present and future problems.

After a first shock, in which the announcement needs to be assimilated, a family tries to learn all about the physical, cognitive and sensorial wellbeing of its own child.

Hence, if they want to receive information on the procedures to develop in order to create a broadly accessible domestic environment they will need to address a specialist.

Nevertheless, not many professionals possess the sensitivity and the expertise for giving correct and specific information to people affected by dystrophin disease. Most of the times, they carry on generalist works, too little measured on the real current and future needs of Duchenne people and their families.

Moreover, it is essential not only for satisfying present necessities, but also for being able to foresee and compensate for future needs. 


\section{The method: a guide to design houses for DMD families}

'Design for All' has been used as planning methodology, associated to all phases of research: from knowing the disease to its degenerative symptoms; from the existing exploratory tools currently on the market to the morphological studies necessary for designing accessible domestic environments.

Once studied and analyzed all the issues related to domestic accessibility for people with specific demands, we have noticed the real problem is ascribable to the lack of communication, of informational instruments, of an accessible and inclusive culture; inasmuch, it is the living context creating more disability than the pathology itself.

Thus, we thought of developing a hard-copy tool supporting both families and specialists and professionals, capable of providing useful, applicable, and scientific information.

The operative instrument through which we designed the manual's graphic interface is the Quality Function Deployment (QFD). QDF has the ambitious task of translating the intangible needs (expectations, fears, dreads, hopes, dreams, ecc.) in measurable quantities through a multidisciplinary approach.

Although such description appears to be much alike to the processes of the User Centered Design, broadly applied to Inclusive Design, it is worth highlighting how in this very context QDF succeeds to provide indications and quantitative parameters able to measure the actual expectations of the involved users, achieving an accurate comparative evaluation among the solutions already available on the market.

Furthermore, thanks to the above-mentioned methodology, it has been possible to arrive to the definition of specific techniques, useful for the conception of the final project's interface: such specifications have been traced thanks to the characteristics and needs of all involved users. This process eventually brings to the increase of product usability and of its perceived quality.

Such methodology has been helpful also for understanding the different necessities of the families and the specialists, and for making them more real and tangible.

This work has had as main goals both the graphic accessibility, through an intelligent interface, and the provision of precise and reliable recommendations, while proposing adequate solutions for people affected by DMD and their families.

\section{Information contents}

In order to develop a useful and applicable manual addressing both the families and the professionals, it has been fundamental to provide information of high operational reliability and great functional quality. Also, our aim was to give elegant and pleasant indications. In fact, many accessible or specific environments targeting disabled people too often renounce to the aesthetics in favor of functionality; it is necessary for the proposed solutions to be operational, flexible, and customizable, but this should not prevent them from being also aesthetically appealing at both sight and use.

Information related to the interactions between the individual and the specific piece of furniture / environment have been gathered together with the medical staff, and then developed through interviews, meetings and conferences. 


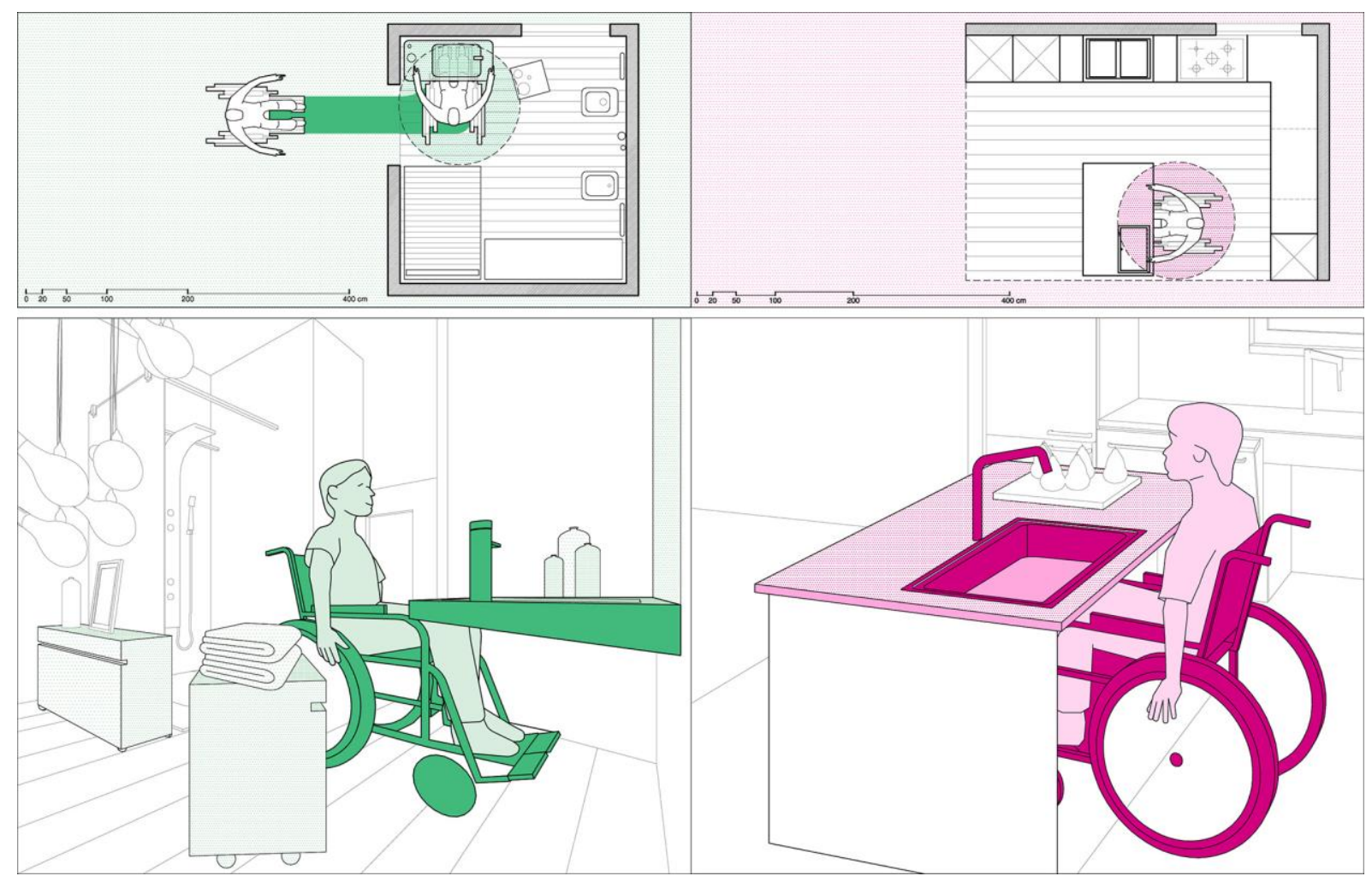

Figure 1. Examples of diagrams in the manual.

Thanks to Parent Project Onlus we have been able to exploit their archive of registered people and families interested in such topics; together with them we undertook a learning and knowledge exchanging process especially on their needs in terms of space and morphology.

Many of the acquired information were summarized in issues tied to the relationship between the supports (physical objects or pieces of furniture) and the spaces for maneuver (according to individual disabilities, or to the kind of technology used by the family).

At first, these relations were carried out especially through interviews, conference calls, or other exchange of material and opinions; after this first phase, we were able to make complex thinking and therefore plan future work. Another fundamental aspect has been to carry on a storytelling process with the involved families, in depth understanding their routines and habits; such process has been undertaken by each member of the family, as the domestic environment will have to accommodate accessible spaces for both the disabled person and the other components of the family.

This operative procedure has further helped us to understand which were the settings and the issues of greater relevance within the house. We then created a list of the actual needs of each family divided room by room, as the very same need can be interpreted in different ways according to the specific environmental context which we experience.

During the whole implementation process of the set of problems, we had proof that the most hindering environments in terms of accessibility were the ones mainly used by the disabled person: the bathroom, the bedroom, and the kitchen. We consequently proceeded to the accurate and specific description of each characteristic connected to the mostly used unmovable supports and pieces of furniture located in the above-stated rooms. As for the bathroom, for instance, we analyzed the toilet and bidet, the sink, the bathtub, the shower, and the complementary elements. 
For each piece of furniture and environment we tried to transmit information related to:

- Legislation: for every analyzed setting, the regulation in force has been studied and from it we deduced the most useful prescriptions according to the disabilities affecting Duchenne children, in order to better understand which recommendations to integrate and which to discard.

- Position: in this section we expressed some advices on how advantageous could be to investigate the environment in relation to the property and to the movements, also for understanding how to arrange the furnishings (both unmovable and mobile) within the domestic context. For this purpose, we studied both the disposition of a certain room (e.g. the bathroom) within the dwelling, as the one of every single unmovable or mobile element (e.g. toilet, bidet, and sink) within the specific room.

- Technical aspects: all performance and dimensional characteristics of the different dwelling's environments have been scrutinized in detail grounding on the demands, needs, and necessities of Duchenne children, and in relation to the progression of the disease. For each piece of furniture we also studied and analyzed the available solutions on the market, in order to establish which are the most appropriate and exhaustive for a complex syndrome such as the dystrophic one.

- Economic aspects: in this section we considered the economic perspective of the previous investigated and illustrated solutions: all aspects which might exponentially increase the costs coming from the adjustment of one's property according to its features.

After completing this last step, we personally met the families to check if our technologies, advices and recommendations had been actually and affectively accessible and adaptable to their life contexts.

\section{Results}

The obtained results are overall positive, both in relation to the design of the communication accessibility of the manual, and to the dissemination of useful information for domestic adjustment in spatial and interior design terms.

In order to obtain a shared appreciation of the graphic interface, we created a multimedia survey addressing all final users: families and professionals. The latter were asked to express their opinion on a five-point scale, referring to specific aspects able to emphasize the manual's design strategies: from the employed font to text colors; from the typologies of the selected images to their dimensions.

From the elaboration of the statistical data we attained a high appreciation from both the two user categories. Families involved in the compilation of the questionnaire were 103; this number corresponds to the $21,65 \%$ of all forwarded forms. Whereas the ones compiled by professionals were 202 on an uncertain total number, as they have been mailed to the Professional Association of Architects of the Ferrara and Bologna provinces, and to the Architect Federation of the EmiliaRomagna region.

In regard of the second objective, we have received quality confirmation on the transmitted information both from families and from professionals. In particular, some families consulted us for 
addressing the accessibility of their dwellings after having examined the manual, or they reported of successful interventions when respecting the advices given in the guide.

\section{Conclusions}

Finally, we tried to develop a product both easy to consult and yet exhaustive for the families; scientific and detailed for the specialists.

The resulting product needs to be considered as a proper design object, in its form and in its contents. However, it represents a sort of design which does not have the aim to astonish buyers, but rather which focuses on the actual functional and communication appreciation of its final users. Being successful in facilitating their lives, simplifying their daily activities, and triggering new scenarios and living conditions based on the real present and future needs represents indeed the final goal.

All book's characteristics have been conceived by posing the individual and its needs at the very center of the project: from using graphic images in support of the text to the typology of the proposed pieces of furniture; from communication strategies to contents.

$17 \exists O N \forall O O N \forall Y$

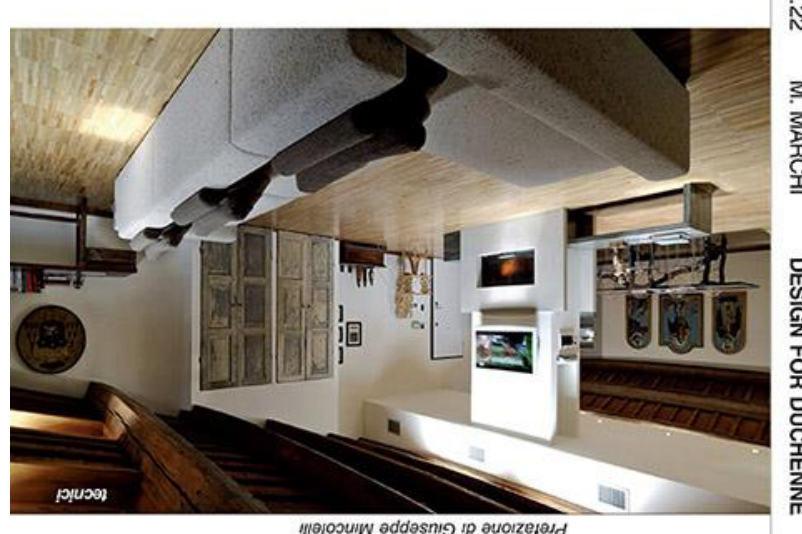

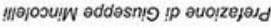

enpeurou IIe sol ubisop luolzęlqe Ip әuolzesnynusu

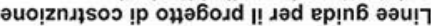

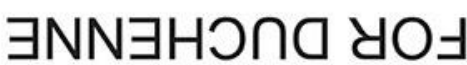

NつIS $\exists 0$

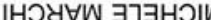

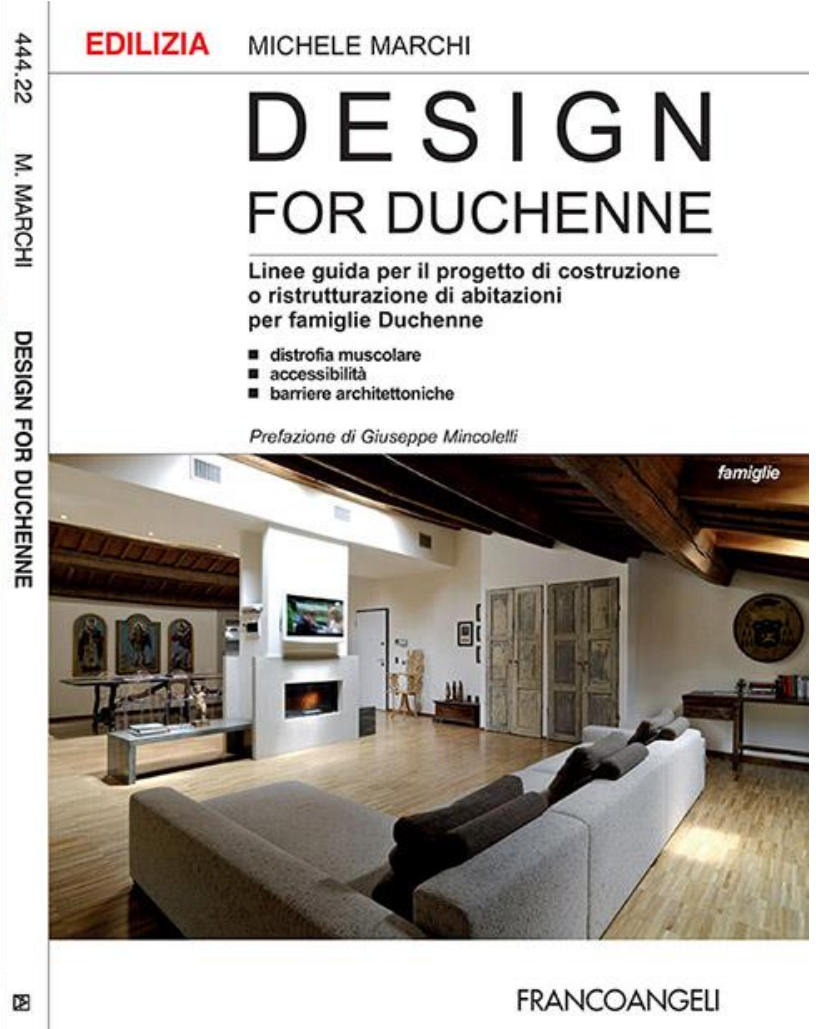

FRANCOANGELI

Figure 2. Cover of the editorial product.

We also tried to impart a methodology, instead of standard and pre-established indications. The current market already provides a broad set of interior design devices and solutions suitable for Duchenne people; it is sufficient to be aware of one's abilities / disabilities and then choose the most appropriate solutions. 
Moreover, it is important to specify that the given indications might be considered proper and exhaustive also for many other pathologies, and motor or functional disabilities; in fact, many of the suggested information can be considered 'accessible' for people on wheelchairs, for mobilityimpaired elderly people, and for individuals affected by diseases restraining the use of the upper limbs.

Finally, we tried to impart a methodology aiming at beauty: users with specific needs do not have to give.

\section{References}

Mincolelli G.: Customer/user centered design. Analisi di un caso applicativo, Maggioli, Rimini, 2008

Mincolelli G.: Design accessibile. Esperienze progettuali e didattiche sul tema del Design for all, Maggioli, Rimini, 2008

University at Buffalo, The State University of New York, Danise Levine, M. Arch. (2003). Center for Inclusive Design and Environmental Access. Universal design New York 2, Idea Publications.

Empler T. (1997). Progettare il comfort urbano e d'interni. Guida ad una progettazione plurisensoriale. Maggioli, Rimini.

Lupacchini A. (2010). Design olistico. Progettare secondo i principi del DfA. Alinea Editrice, Firenze.

Momo P.P., Francesco Zucchelli F. (1997). Design to succes. Come concepire e progettare prodotti vincenti. Isedi, Milano, 1a ed.

Arenghi A. (2006). Design for all. Progettare senza barriere architettoniche. UTET, Torino.

Argentin I., Clemente M., Empler T. (2004). Eliminazione barriere architettoniche, progettare per una utenza ampliata. DEI, Tipografia del Genio Civile.

Buzzelli G.E. (2004). Progettazione senza barriere. Oltre i confini della disabilità. Concetti e criteri operativi di universal design, architectural engineering e assistive tecnnology. Sistemi editoriali.

Canalini R., Ceccarani P., Storani E., Von Prondzinski S. (2005). Spazi incontro alla disabilità. Progettare gli ambienti di vita nelle pluriminorazioni sensoriali. Erickson, Trento.

Casiddu N. (2004). Anziani a casa propria. Linee guida per adeguare spazi ed oggetti. FrancoAngeli, Milano.

Del Zanna G. (2005). Progettare l'accessibilità. Edizioni Grafill, Palermo.

Di Sivo M., Schiavone E., Tambasco M. (2005). Barriere architettoniche. Guida al progetto di accessibilità e sicurezza dell'ambiente costruito. Alinea editrice, Firenze.

Fantini L. (2011). Progettare i luoghi senza barriere. Manuale con schede tecniche di soluzioni inclusive. Maggioli, Rimini.

Fischer J., Mauser P. (2009). Construction and design manual. Accessible Architecture, Dom publishers.

Michael R. Bloomberg, Mayor, The City of New York, Sustainable New York. Implementing sustinable design in the city's public works

Trioschi D. (2007). Una casa su misura. Domande e risposte per migliorare l'accessibilità domestica. Centro regionale ausili Bologna, Regione Emilia Romagna

Vescovo F. (1990). Accessibilità e barriere architettoniche. Maggioli, Rimini. 
About the Authors:

Michele Marchi_architect and Ph.D. He graduated in 2010 at the Department of Architecture of Ferrara. He is author of articles, speaker at national and international conferences and consultant for public and private associations on issues regarding physical accessibility, cognitive and sensory.

Giuseppe Mincolelli_Architect and designer. Specialized in User-Centered and Inclusive Design, Associate Professor of Design at the Department of Architecture of the University of Ferrara. Numerous patents, publications and awards in Italy and abroad. 